\title{
REFLEXIONES Y PRESENTACIÓN DEL PROYECTO "PROMOCIÓN DE LA SALUD SEXUAL, PREVENCIÓN Y DETECCIÓN DEL VIH EN PERSONAS JÓVENES DEL GRAN ÁREA METROPOLITANA DE COSTA RICA"
}

\author{
REFLECTIONS AND PRESENTATION OF THE PROJECT \\ "PROMOTION OF SEXUAL HEALTH, PREVENTION AND DETECTION \\ OF HIV IN YOUNG PEOPLE OF THE GREAT METROPOLITAN AREA \\ OF COSTA RICA”
}

\section{Camila Anaité Cuevas Barberousse*}

\section{RESUMEN}

El presente artículo reúne reflexiones en torno a la propuesta presentada por la Asociación Demográfica Costarricense a la Junta de Protección Social titulada "Promoción de la Salud Sexual, prevención y detección del VIH en personas jóvenes del Gran Área Metropolitana de Costa Rica", ejecutada durante el año 2017. Por medio de la observación participante, se sistematiza y describe los fundamentos teóricos y prácticos del proyecto, así como, las referencias nacionales contextuales sobre los derechos sexuales y reproductivos en la prevención y la detección del VIH/Sida en Costa Rica. La posición teórica adoptada es el feminismo interseccional, desde el cual se construyen y aportan reflexiones al quehacer de los movimientos feministas contemporáneos, específicamente en la integración de una política multisectorial y anticlasista.

PALABRAS CLAVE: COSTA RICA * EDUCACIÓN * DERECHOS SEXUALES * DERECHOS REPRODUCTIVOS * VIH/SIDA

\section{ABSTRACT}

This article gathers reflections on the proposal presented by the Costa Rican Demographic Association to the Social Protection Board entitled "Promotion of Sexual Health, prevention and detection of HIV in young people in the Great Metropolitan Area of Costa Rica", executed during the year of 2017. The theoretical and practical foundations of the project, as well as the contextual national references on sexual and reproductive rights

Estudiante de Sociología de la Universidad de Costa Rica, Costa Rica. cuevasbarberousse@gmail.com 
in the prevention and detection of HIV/AIDS, are systematized and described through the participant observation methodology. The theoretical approach is critical intersectional feminism, from which we create reflections and contribute to the work of contemporary feminist movements, specifically in the integration of multisectoral and anti-class politics.

KEYWORDS: COSTA RICA * EDUCATION * SEXUAL RIGHTS * REPRODUCTIVE RIGHTS * HIV/AIDS

\section{INTRODUCCIÓN}

El presente artículo expone la propuesta presentada por la Asociación Demográfica Costarricense (ADC, 2015) a la Junta de Protección Social (JPS), titulada "Promoción de la Salud Sexual, prevención y detección del viH en personas jóvenes del Gran Área Metropolitana de Costa Rica”, ejecutada durante el año 2017. El objetivo general del proyecto consistió en contribuir a reducir la vulnerabilidad ante el VIH $y$ el sida entre la población joven que asiste a colegios nocturnos en los cantones con mayor incidencia ${ }^{1}$, por medio de talleres participativos impartidos a estudiantes $y$ miembros del personal docente $y$ administrativo de los centros educativos. Como parte de dicha estrategia y en complemento a la capacitación, se administró la prueba de anticuerpos contra el VIH a las personas asistentes mayores de edad, bajo consentimiento informado $y$ voluntario.

La formulación y ejecución de este proyecto estuvo a cargo de un equipo de profesionales de la salud, ciencias sociales y económicas ${ }^{2}$. A pesar de su conformación grupal, cabe señalar que las reflexiones suscitadas en el presente artículo se han elaborado en la individualidad, por lo que las experiencias, las interpretaciones y los posicionamientos críticos del hacer político y feminista no representan al conjunto de los profesionales o al de las instituciones involucradas. Se debe agregar que el diálogo constante en la práctica y el vínculo con las compañeras de trabajo y participantes,

1 A la fecha de implementación del proyecto, se identificó los cantones de Alajuela, Desamparados, Goicoechea, Heredia, San José y Tibás.

2 Como parte del equipo en el área de las ciencias sociales, la autora se integró bajo el puesto de Educadora de la ADC. permitió forjar canales de construcción de conocimientos multidireccionales que derivan, de múltiples formas, en las ideas aquí expuestas.

La posibilidad de formular un proyecto con financiación estatal surge de la consolidación y ampliación de los instrumentos internacionales en materia de derechos humanos desde la Declaración Universal de 1948. Los derechos humanos, entendidos como los ordenamientos jurídicos nacionales e internacionales, son ejes centrales en diversos movimientos sociales contemporáneos, que mediante su articulación con reivindicaciones de diversos sectores, han logrado avances en demandas colectivas e individuales. De este modo, la construcción de una sociedad democrática en Centroamérica ha impulsado la búsqueda de un marco de integración social, económica, política y cultural que amplía el concepto de ciudadanía (Raupp, 2001) y motiva la profundización teórica y práctica de cuestiones concretas relacionadas, en este caso, con el género y la sexualidad.

El avance en los derechos sexuales $y$ reproductivos (DESER) se relaciona, en un campo no exento de polémica, a esfuerzos reflexivos cada vez más articulados y visibles de los movimientos feministas, gays, lésbicos, transgéneros, transexuales, intersexuales $y$ de trabajadoras sexuales. En Centroamérica, los avances en este aspecto son muchas veces atropellados por realidades apabullantes que se fermentan en los cuerpos colonizados, sumergidos en las realidades del imperialismo capitalista, del neoconservadurismo y del neoliberalismo económico. Aunado a las ficciones socio-políticas (Preciado, 2014) en relación al género y a la sexualidad en un contexto patriarcal, ciscentrado $y$ heteronormado, el cual regula por medio de dispositivos de poder (Foucault, 1975), los cuerpos y los comportamiento eróticos normalizados y aquellos excluidos. 
El resultado de dichos discursos son varios, lo cual da cabida a disertaciones racistas, xenofóbicas, homolesbotransfóbicas y aporofóbicas que se retroalimentan de nomenclaturas eclesiásticas, médicas, psiquiátricas y estatales. La violencia a la cual se ven insertos los cuerpos, en interseccionalidad de sus propias características sociales, arremeten realidades precarizadas y marginalizadas que no responden a una solución unidimensional para su entendimiento y su agenciamiento. En este contexto, es que se plantea, desde las bases institucionales, avecinamientos políticos que busquen gestionar sus propios actos micropolíticos por medio del reconocimiento de la capacidad histórica de los cuerpos (Alpizar, 2017). De esta manera, hacer una apuesta por un proyecto feminista "requiere atender a cómo las diferentes opresiones, a cómo el racismo, el clasismo y el heterosexismo se (re)producen violentamente en nuestra cotidianidad, $y$ evitar la salida fácil de fijar a priori una exclusión primaria" (Romero et al., 2005, p.24)

En este ámbito, la ADC es una organización de la sociedad civil sin fines de lucro fundada en el año 1966, creada con el fin de mejorar el disfrute de la salud sexual y reproductiva en Costa Rica y declarada Bien Público para los Intereses del Estado en 1983. Propone y emprende proyectos diversos, dirigidos prioritariamente a poblaciones en pobreza y vulnerabilidad, que giran en torno a actividades como las jornadas de capacitaciones y sensibilización sobre el Virus de Inmunodeficiencia Humana (VIH), el Síndrome de Inmunodeficiencia Adquirida (SIDA), diversidad sexual, DESER, métodos anticonceptivos, servicios de acompañamiento y consejería psicosocial, entre otros.

Los proyectos de la ADC comprenden tres ejes principales de acción: el trabajo en campo (por medio de capacitaciones, talleres participativos y campañas de visibilización-acción), las actividades de investigación y actualización teórica y metodológica en abordajes científicos sobre la salud sexual y reproductiva; $y$, por último, actividades de incidencia política destinadas a promover cambios legislativos y normativos que mejoren el ejercicio de los DESER (ADC, enero de 2015). El financiamiento de dichos proyectos se sistematiza en su Plan Anual de Trabajo, al ser una de sus fuentes principales la Federación Internacional de Planificación Familiar (IPPF por sus siglas en inglés), de la cual es miembro desde 1967. Asimismo, cuenta con el apoyo intermitente del Programa Regional REDCA+, el Programa Conjunto de Naciones Unidas sobre el VIH y sida (ONUSIDA) y el Ministerio de Salud.

En el caso particular del proyecto titulado "Promoción de la salud sexual, prevención y detección del VIH en personas jóvenes del Gran Área Metropolitana de Costa Rica", se contó con la financiación de la Junta de Protección Social $y$ de un convenio con el Laboratorio Clínico de la Universidad de Costa Rica, procesos que se propone presentar en este artículo, al realizar un recorrido por medio de los posicionamientos teóricos y metodológicos empleados, así como, los resultados finales.

\section{SITUACIÓN Y ATENCIÓN AL VIH/SIDA EN COSTA RICA}

La prevalencia del VIH se ha expandido rápidamente a nivel mundial, demandando, desde diferentes latitudes, prontas respuestas sanitarias. Sin embargo, dada las actitudes culturales y los prejuicios hacia las personas VIH-positivas en Costa Rica, hasta mediados de los años 80, las investigaciones y el desarrollo de políticas públicas de financiamiento e información se vieron menoscabadas.

No es hasta el año 1987 que se accionó al respecto a nivel nacional, fecha valorada como tardía para dar respuesta al sida y proteger a las poblaciones clave de mayor riesgo. Concomitante, la represión y la violencia de derechos contra la población LGBT aumentó, se intensificó las redadas policiales en los centros de reunión nocturnos de la comunidad, entre otras medidas, lo cual dio cuenta de la red cultural conservadora y el ligamen entre las prácticas sexuales, eróticas y reproductivas en el imaginario colectivo (Schifter, 1998). Ciertamente, la apología entre la carga simbólica católica estatal repercutió en la dirección primera de las políticas públicas en respuesta al VIH, confinando la respuesta a prácticas de violencia policíaca $y$ a la moral hegemónica. 
La aparición del tratamiento antirretroviral combinado fue habilitado en Costa Rica en el año 1996 e instaurado en el marco legal para garantizar la atención integral, lo que permitió que un mayor número de personas tuvieran acceso económico para el tratamiento. Según el informe "La situación del VIH/sida en Costa Rica" (Chamizo et al., 2004) el gasto y el financiamiento estatal en la materia ha aumentado sistemáticamente desde el periodo de 1998 hasta el 2002, tras el cual se registra un decrecimiento motivado por la disminución del costo del tratamiento antirretroviral a nivel mun$\mathrm{dial}^{3}$. Otros gastos e inversiones contempladas son el financiamiento a iniciativas externas, "en información, educación y comunicación, (que se) reparten entre el Gobierno Central que desarrolla más de la mitad del gasto, el seguro social y las ONGs" (Chamizo et al., 2004, p.25).

El Plan Estratégico Nacional (PEN) de VIH y sida para el periodo 2010-2015, a partir del cual se formuló el proyecto, contempla a las personas jóvenes como una de las poblaciones más vulnerables ante el VIH y sida, en razón del inicio de su vida sexual y las altas tendencias a las prácticas $y$ conductas sexuales catalogadas de alto riesgo, así como a una baja percepción de amenaza de trasmisión ante las Infecciones de Trasmisión Sexual (ITS). Dichos comportamientos están íntimamente ligados a la desinformación o deformación comunicacional ${ }^{4}$ en materia sexual educativa, situación que profundiza la marginalización y las violencias interseccionales que atraviesan los cuerpos, a considerar variables socioculturales y económicas como la pobreza, la exclusión social, la condición migratoria irregular, el bajo nivel educativo, entre otras.

De la misma manera, en los Objetivos y Compromisos de la Declaración Política sobre

3 En el ámbito internacional, Costa Rica fue partícipe en la promoción de la declaración de los antirretrovirales como patrimonio de la humanidad.

Parte de la campaña de prevención del viH/sida de la Caja Costarricense de Seguro Social (ccss) consiste en promover la abstinencia sexual como el principal método de prevención al contagio, en conjunto a la fidelidad mutua. Se pueden ver los videos de la campaña en la dirección web https:// www.ccss.sa.cr/sida el VIH y el sida (Naciones Unidas, 2016), se encuentra especificada la importancia de reducir la trasmisión sexual del virus, identificando a la juventud como prioridad en la prevención por medio de herramientas informativas, en concordancia con los datos nacionales y la consideración simultánea de la detección temprana como clave en el proceso de atención. Sin embargo, actualmente el acceso es limitado, dada la negativa en educación sexual en los centros educativos y el bajo impacto de las campañas asistencialistas. En esta línea, en el Plan Nacional de Salud 2016-2020, emitido desde el Ministerio de Salud (2016b), se citan las declaraciones señaladas en el informe sobre "La Salud en el Mundo 2003", el cual señala la importancia del compromiso de grupos organizados en el desarrollo de políticas públicas participativas y simultáneamente respetuosas de los derechos y de la diversidad de criterios.

Las recomendaciones anteriores contrastan con los resultados de la Encuesta Nacional de Salud Sexual y Salud Reproductiva (Ministerio de Salud, 2010a), en la cual se evidencia el desconocimiento circundante al VIH e ITS, en tanto 1 de cada 4 personas menores de 30 años de edad piensa que "el viH puede trasmitirse por el sudor o la saliva", 1 de cada 5 afirma que "el VIH puede trasmitirse por la picadura de un mosquito" y, 1 de cada 6 , piensa que "el viH puede trasmitirse mediante servicios sanitarios”. Asimismo, como señala Schifter (1998), el velo de secretismo que envuelve a las ITs y al VIH es amplio, se sigue asociando al VIH con las orientaciones sexuales, en tanto las campañas mediáticas masivas, comunicacionales y los poderes eclesiásticos asociaron el contagio del virus con un castigo divino contra la población LGBT, los promiscuos o los desviados.

En esta última encuesta se indica que del total de personas con vida sexual activa, aproximadamente, el $51 \%$ de mujeres afirma haber empezado sus relaciones antes de los 18 años, mientras que en el caso de los hombres dicha cifra se eleva a un 68\%. En la Primera Encuesta Nacional de Juventud (Consejo de la Persona Joven, 2007), se especifica que aproximadamente el $76 \%$ de las personas jóvenes (entre 15 a 24 años) han tenido relaciones sexuales. 
La vulnerabilidad ante el VIH, que se evidencia en las cifras anteriormente expuestas, es respaldada por los datos epistemológicos brindados por el Ministerio de Salud (2019), los cuales describen que más de la mitad de los casos de VIH positivos entre los años 2002 y 2017, corresponden a personas menores de 34 años, mientras que el intervalo entre los 25 y los 34 años es el que presenta la mayor incidencia, por lo que dichos datos indican que los contagios del virus se están efectuando en tempranas edades. Asimismo, se registra un aumento significativo en las tasas de contagio, al haber triplicado el número de incidentes en este periodo.

Con respecto al proyecto de la $\mathrm{ADC}$ presentado en este artículo, se utilizó como referencia los datos de la distribución demográfica de las personas seropositivas a nivel nacional, con la finalidad de delimitar la zonas de trabajo y como justificación a la acción política. Con este fin, se tomó como referencia la información del Ministerio de Salud (2016a), el cual contabilizaba la mayor incidencia de habitantes seropositivos en el Gran Área Metropolitana (GAM), con un total de 4727 habitantes, lo cual representa aproximadamente el $71 \%$ del total de los casos reportados a nivel nacional. A partir de esta primera delimitación, la cual ubica los medios urbanos como principal interés, se prosiguió a la identificación de la distribución de la incidencia por provincia, con el objetivo de identificar con mayor precisión las zonas de implementación del proyecto. Del total de personas seropositivas en la GAM, el 48,5\% del total reside en San José, el 10,2\% en Heredia, el 7,7\% en Alajuela y el 5,2\% en Cartago.

Por lo tanto, se justifica las zonas de trabajo por parte de las organizaciones involucradas, así como la base de conocimientos básicos sobre el conocimiento y agenciamiento de las personas jóvenes sobre el VIH y las ITS.

\section{DESCRIPCIÓN GENERAL DEL PROYECTO}

\section{A) ASPECTOS GENERALES}

El proyecto brindó servicios de educación integral en derechos sexuales y reproductivos con énfasis en la prevención del VIH, dirigido a estudiantes, profesorado y personal administrativo de colegios públicos nocturnos del Gran Área Metropolitana. Los servicios se dividen en dos ejes principales: el primero, mediante un programa de capacitación conformado de 3 talleres participativos, $y$ el segundo, a través de la realización de la prueba de detección del VIH en el sitio.

La elección de impartir los servicios en los colegios nocturnos responde a criterios de selección de la población meta. En tanto, los proyectos educativos y preventivos costarricenses no suelen ser aplicados en horario vespertino y nocturno, a pesar de que los estudiantes en su mayoría son adultos jóvenes y, por lo tanto, representativos del grupo de edad con mayor incidencia de infección por viH. Asimismo, se da un cruce de variables por las cuales los estudiantes asisten a horarios nocturnos, ya sea por la combinación con contratos laborales, indispensables para su manutención, o bien, por la necesidad de cuido familiar y trabajo doméstico durante el día, entre otras razones.

La población beneficiaria se estableció entre los 18 y 30 años de edad, estudiantes de colegios nocturnos de los cantones con mayor incidencia de VIH. Estas personas se distribuyeron en un total de 17 colegios nocturnos en los cantones de San José, Tibás, Desamparados, Goicoechea, Heredia y Alajuela. Se estimó un alcance total de 1500 capacitaciones para un estimado de 510 personas jóvenes participantes. Asimismo, se pretendía un número similar en el número de pruebas de detección del viH, distribución que más adelante se especificará. En cada uno de los colegios participantes, se buscaba la capacitación de al menos 3 miembros clave del personal docente $y$ administrativo, para un total de 51 funcionarios, en espera de que, en un futuro cercano, dichas personas fueran capaces de replicar las charlas y dar seguimiento a la temática a lo interno de los centros.

Los talleres participativos o las capacitaciones (divididos en 3 bloques de 2 horas cada uno) y la posibilidad de realizar la prueba de VIH tras finalizar las actividades, se desarrollaron con previa coordinación y planificación con las autoridades correspondientes de cada centro educativo. Dicho contacto se entabló tras la 
comunicación y aprobación por parte de las Direcciones Regionales de Educación, en este caso, de Alajuela, Desamparados, Heredia, San José Central y San José Oeste. De igual manera, antes de entablar cualquier labor del proyecto, se realizaba una visita o varias al centro educativo, con el fin de presentar a las encargadas de este e iniciar el proceso de comunicación e intensión. Cabe destacar que la aprobación y la financiación previa de la Junta de Protección Social y el Ministerio de Salud serían clave en la comunicación y el acercamiento a los centros educativos, en tanto genera un respaldo del contenido, trayectoria e impacto del proyecto presentado, así como, el interés general en su realización.

Estas labores estuvieron a cargo de tres funcionarias de la ADC (la coordinadora y 2 promotoras). La primera sería la responsable de los trabajos de coordinación y de procesos administrativos, así como de capacitación en caso de ser necesario. Las promotoras estuvieron a cargo de la realización de las visitas y de los talleres en los centros educativos, así como del orden de las evaluaciones administradas a las personas participantes antes y después de los talleres ${ }^{5}$.
La matrícula total de los centros educativos seleccionados en el 2014, reportaban un total de 7545 estudiantes $^{6}$. De esta manera, se distribuyó entre los colegios el total de la población beneficiaria (1500 personas) en proporción a su matrícula del año reportada. Se redondeó al múltiplo más cercano de 30 (promedio de estudiantes por sección), por lo que se estableció la siguiente distribución, contenida en la tabla 1.
$5 \quad$ Antes de iniciar las capacitaciones se aplicaba una encuesta de conocimientos sobre los derechos sexuales y reproductivos, conocimientos generales en sexualidad, ITS y VIH/Sida. Al final de las 3 sesiones, se aplicaba el mismo cuestionario. El fin era cuantificar el aprendizaje en dichas materias antes y después de las actividades $y$, por ende, evaluar el impacto inmediato de las mismas. Posteriormente, se realizaron llamadas telefónicas a aquellas personas que autorizaron sus datos personales al momento de realizarse la prueba de detección del viH.
$6 \quad$ El dato del total de personas matriculadas se obtuvo al sumar los totales de matrícula de cada centro educativo concerniente, los cuales se obtuvieran por consulta directa con la dirección y administración de cada centro de enseñanza. 


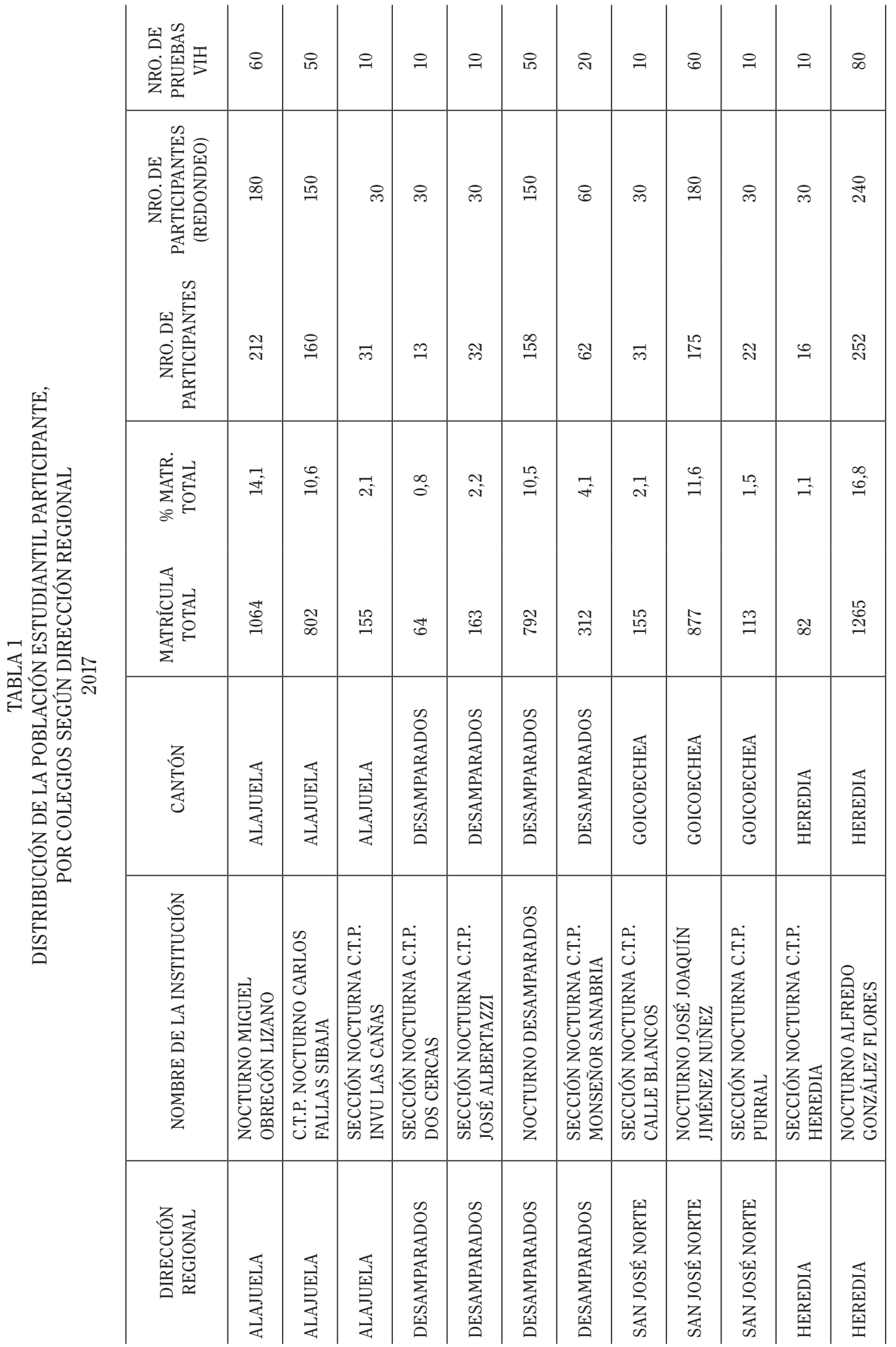




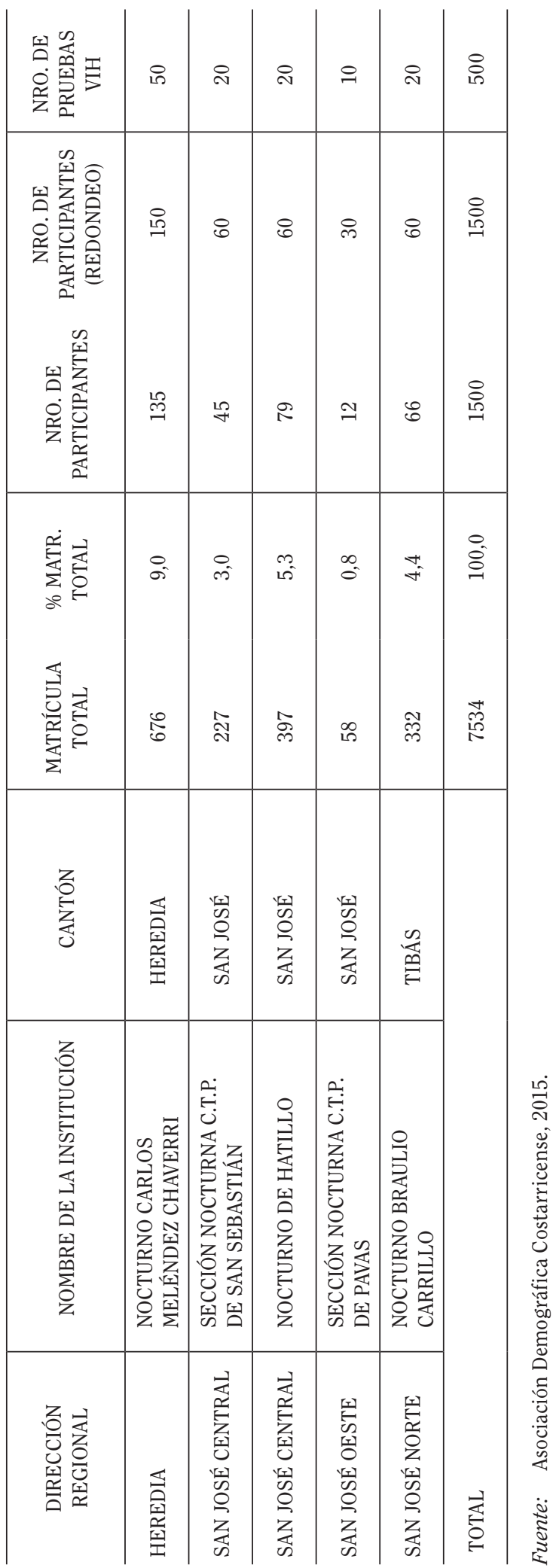


Además, se asume un convenio con el Laboratorio Clínico de la Universidad de Costa Rica, el cual facilitó el traslado de personas microbiólogas o técnicas y los equipos de análisis en la detección del viH bajo la técnica ELISA. Esto habilitó la posibilidad de realizar la prueba tras haber concluido los talleres de capacitación en los mismos establecimientos educativos, bajo previa firma de consentimiento y explicación de los procedimientos, derechos $y$ deberes inmiscuidos.

B) METODOLOGÍA Y CONTENIDO DE LAS CAPACITACIONES

El proceso de sensibilización, capacitación y consejería se diseña a partir de un modelo pedagógico constructivista basado en los enfoques de derechos humanos, género, generacional y diversidad. Se toma como referencia los convenios, los protocolos y las leyes nacionales ${ }^{7}$ como internacionales en el fortalecimiento del área de la salud sexual y reproductiva.

Las capacitaciones se dividieron en 3 talleres de 2 horas cada uno, dependiendo de las facilidades o dificultades en la coordinación con cada centro educativo y grupo de trabajo. Cada grupo se estimó en aproximadamente 30 personas. En la tabla 2, se especifica por cada uno de los colegios seleccionados el total de participantes, el número de grupos que se abarcó y el número de sesiones realizadas.

$7 \quad$ Estas referencias se pueden consultar en el segundo capítulo del Plan Estratégico Nacional (PEN) en VIH y sida, 2016-2021 del Ministerio de Salud (2016a) costarricense. 


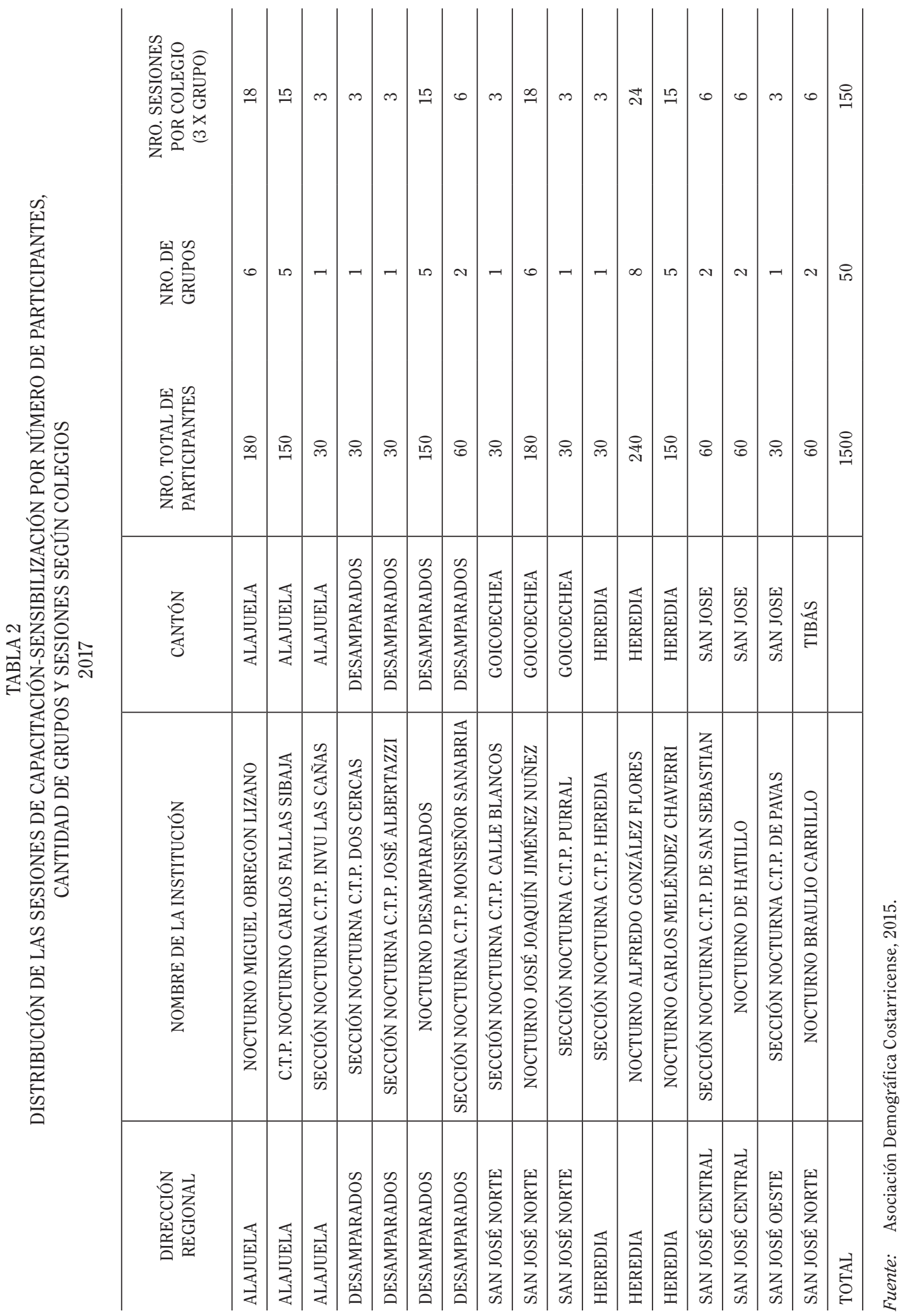


Las herramientas utilizadas en las sesiones son dinámicas participativas de preferencia de la capacitadora, las cuales podían variar y combinarse entre presentaciones digitales, papelógrafos, mesas redondas, debates, participación abierta, entre otras. Se instó en cada uno de los procesos de aprendizaje incorporar dinámicas colectivas e individuales, con el fin de promover diferentes métodos de retención y atención, así como, la creación de espacios dinámicos y entretenidos. Estos últimos aspectos eran fundamentales dada las condiciones de cansancio tras jornadas laborales (formales o informales) en el horario diurno de la población participante. Al final de cada una de las sesiones $y$ durante los recesos (a convenir con el grupo participante), se abrían espacios de consejería individual. El contenido de las sesiones se especifica a continuación:

\section{SESIÓN 1}

Giró en torno a la introducción de la sexualidad humana, en tanto se brinda un repaso de los conceptos y postulados generales de sexo, género, sexualidad, orientación sexual e identidad de género. Asimismo, se profundizó en las implicaciones de sus variables en la cotidianidad costarricense, lo cual motivó discusiones en torno a las posibilidades de existencia y los discursos circundantes. Se abarcó de esta manera las vivencias, los mitos y las realidades sobre la sexualidad.

\section{SESIÓN 2}

Se introdujeron, tras la revisión de la materia de la sesión pasada, las ITs con énfasis en el VIH. Se deliberó sobre las principales ITs curables $y$ no curables, los tratamientos efectivos para cada una de estas, sus síntomas y sus formas de prevención. Se ahondó en definir el viH/sida, las formas de prevención y trasmisión. Para este cometido se brindaron folletos informativos sobre el uso correcto del condón, contacto de centros donde realizarse la prueba e información general. Asimismo, se dio una demostración de la forma correcta de utilizar los condones masculinos y femeninos, dando tiempos de consultas grupales, participación integral y aclaración de dudas o comentarios.

Dependiendo de la disponibilidad del grupo y de la previa coordinación, en una sala o en un aula aparte, se realizaron las pruebas de sangre por el Laboratorio Clínico de la Universidad de Costa Rica. Con este fin, se abrió un espacio al finalizar la sesión, para explicar el contenido del Consentimiento Informado, al igual que las implicaciones de confidencialidad $y$ responsabilidad de la prueba. Tras las explicaciones y firmas se procedió al tamizaje.

\section{SESIÓN 3}

En la última sesión se profundizó sobre los métodos anticonceptivos, tanto de barrera como los de no barrera. Se introdujeron los métodos más utilizados en Costa Rica y su posible acceso en los centros de salud públicos y privados. Por último, se abrió un espacio para resolver consultas o temas específicos que las personas participantes deseaban explorar.

Al final de la sesión se entregaron los resultados de las pruebas de detección del VIH en consejerías individuales y confidenciales. En caso de no tener los resultados debido a los tiempos con el laboratorio y la programación de sesiones, se estableció una fecha futura para la entrega de estos de forma personal.

\section{C) FUNCIONAMIENTO DE LAS PRUEBAS DE DETECCIÓN DE ANTICUERPOS CONTRA EL VIH}

En la realización de las pruebas de detección del VIH se siguió un cuidadoso protocolo de consejería y de atención. Las pruebas debían estar sujetas en todas las circunstancias a un entendimiento completo de las implicaciones, responsabilidades $y$ derechos. De esta manera, en la sesión que se propuso la opción de realizarse sin ningún costo la prueba, se debió abarcar la información general y específica referente al VIH/sida. De la misma manera, se debió garantizar que la persona sea mayor de edad o en su defecto poseer la autorización de su(s) tutor(es/as).

La firma $y$ la lectura del Consentimiento Informado, documento oficial de la ADC, donde se especifican los procedimientos y los 
derechos de la persona firmante, es obligatorio. Se incluyeron los datos personales de la persona interesada en dos formularios idénticos, uno de los cuales quedó en propiedad de la capacitadora de la ADC y el otro a manos de la persona interesada. Dicho formulario se mostró al momento de entrar a la sala donde se ubicaban los encargados de la Universidad de Costa Rica, quienes procedían a extraer una muestra de sangre. Tales muestras fueron con el personal de la Universidad directo a los laboratorios. Al tener los resultados listos, ya sea la coordinadora o las personas educadoras se trasladaron al laboratorio convenido en búsqueda de los resultados, los cuales se entregaron en un sobre sellado. Este sobre no se abrió hasta el día convenido con el centro educativo, momento en el cual se otorgó, de manera confidencial y personal, el resultado. Se daba consejería y explicación sobre los datos presentados en el examen, evacuando dudas $y$ dando seguimiento a los resultados reactivos, otorgando el acompañamiento necesario y la vinculación con la ccss para el respectivo seguimiento $y$ tratamiento.

\section{RESULTADOS FINALES DEL PROYECTO}

Los resultados obtenidos del proyecto se cuantificaron en número de personas capacitadas, funcionarios de los centros educativos $y$ pruebas de detección del VIH procesadas. Estos datos fueron otorgados a los representantes de cada centro directivo involucrado en el proceso $y$ a las contrapartes institucionales por parte de la coordinación y las educadoras de la ACD.

En tanto, la cantidad de personas funcionarias capacitadas, se cuenta con un total de 75 en la primera sesión y 70 en la segunda sesión, para una suma de 145 personas. Estos datos sobrepasan ampliamente los estimados en la formulación primera, en la cual se pretendía atender a un aproximado de 51 personas de forma ideal. La cantidad de estudiantes capacitados y capacitadas asciende a 729 en la primera sesión, 656 en la segunda sesión y 636 en una tercera sesión. Esto equivale a un total de 2021 sesiones impartidas. La meta en la formulación rondaba a las 500 personas y 1500 sesiones.
Respecto a las pruebas realizadas, hubo un total de 467 resultados no reactivos y 2 resultados reactivos confirmados, para un total de 469 pruebas de detección de anticuerpos contra el viH realizadas.

\section{REFLEXIONES FINALES}

La elaboración y la ejecución de un proyecto de gran impacto a partir de las posibilidades públicas es una realidad. El contenido y el sustento de los derechos humanos con énfasis en los derechos sexuales y reproductivos, que han sentado las bases de políticas públicas nacionales, permiten las reflexiones teóricas y metodológicas de aplicación directa. Replantear las bases de la opresión por medio de un repensar de los conceptos clave de las sexualidades, posibilita un primer acercamiento radical $^{8}$ que contribuya "a la acuciante tarea de crear pensamiento preciso, humano y auténticamente liberador sobre el sexo" (Rubin, 1984).

En última instancia, la gestación de cambios socioculturales es difícilmente cuantificable a corto o mediano plazo, pero es plausible en tener impactos positivos en la ampliación y la promoción de políticas públicas en temas relacionados a los DESER. Asimismo, el carácter progresivo de los derechos humanos es inalienable, siempre y cuando la necesidad de atención inmediata en materia de salud corporal y mental apremien, las discusiones aledañas tendrán que ser tratadas, en tanto el repensar de la vida sexual y las manifestaciones eróticas y laborales, como el plantear el derecho al aborto, los derechos laborales de las trabajadoras sexuales, la producción y el consumo de la pornografía, las prácticas eróticas sadomasoquistas, la existencia y los derechos de cuerpos trans $^{9}$, entre otros.

Por lo tanto, el plantear la educación sexual integral con una perspectiva de género

8 Se entiende radical en sentido a la teoría expuesta por Rubin (1984), en su obra titulada "Reflexionando sobre el sexo: notas para una teoría radical de la sexualidad".

9 Se entiende trans como abreviación de cada expresión genérica y corporal que transgrede la cisnormatividad. 
que supere los discursos taxológicos biologicistas de las existencias duales, es un reto en la formación docente $y$ en el accionar político que busque el agenciamiento crítico de las categorías genéricas de entendimiento médico-psiquiátrico de las expresiones sexuales. Los retos que esto conlleva en su formulación, sensible a un entorno nacional colonizado y evangelizado, denota la deuda de los movimientos feministas en repensar la apertura temática y autocrítica de los privilegios que atraviesan los discursos hegemónicos en su seno.

\section{REFERENCIAS}

Alpizar, M. (2017). Actos micro-políticos en el abordaje psicosocial en el Progreso de Puntarenas. Anuario CIEP, 115-137.

Asociación Demográfica Costarricense [ADC]. (2015). Promoción de la salud sexual, prevención y detección del VIH en personas jóvenes del Gran área Metropolitana de Costa Rica 2015-2016.

Asociación Demográfica Costarricense [ADC]. (enero de 2015). Página web principal. http://adc-cr.org/

Chamizo, A., Salas, J. y Cruz, M. (2004). La situación del VIH/SIDA en Costa Rica. Organización Panamericana de la Salud.

Consejo de la Persona Joven. (2007). Primera Encuesta Nacional de Juventud.

Foucault, M. (1975). Vigilar y castigar. Biblioteca Nueva.

Ministerio de Salud. (2010a). Encuesta Nacional de Salud Sexual y Salud Reproductiva.

Ministerio de Salud. (2010b). Plan estratégico Nacional (PEN) VIH y sida 2011-2015.

Ministerio de Salud. (2016a). Plan Estratégico Nacional en VIH y sida 2016-2021.

Ministerio de Salud. (2016b). Plan Nacional de Salud 2016-2020.
Ministerio de Salud. (2019). Hoja informativa 3 ¿Por qué atender VIH/SIDA y juventud? https://ministeriodesalud.go.cr/index. $\mathrm{php} / \mathrm{material-educativo/enfermedades/}$ trasmision-sexual/enfermedades-vihsida/vih-sida-hojas-informativas

Naciones Unidas. (2016). Declaración Política sobre el VIH y el SIDA: en la vía rápida para acelerar la lucha contra el VIH y poner fin a la epidemia del SIDA para 2030. Resolución aprobada por la Asamblea General el 8 de junio de 2016.

Preciado, P. (2014). Las subjetividades como ficciones politicas. (K. Rodante, entrevistador). [Video]. Youtube. https://www. youtube.com/watch? $v=\mathrm{R} 4 \mathrm{GnRZ7}$ - w4

Raupp, R. (2001). Apuntes para un derecho democrático de la sexualidad. Libertades Laicas.

Romero, C., García, S. y Bargueiras, C. (2005). El eje del mal es heterosexual. Figuraciones, movimientos y prácticas feministas queer. Traficantes de sueños. https://www.traficantes.net/sites/default/ files/pdfs/El\%20 eje $\% 20$ del $\% 20$ malTdS.pdf

Rubin, G. (1984). Reflexionando sobre el sexo: notas para una teoría radical de la sexualidad. https://museo-etnografico.com/pdf/ puntodefuga/150121gaylerubin.pdf

Schifter, J. (1998). La formación de una contracultura: homosexualismo y Sida en Costa Rica. ILPES.

Fecha de ingreso: 22/07/2019 Fecha de aprobación: 04/05/2020 
